Article

\title{
Temperature and Pressure Effects of Desalination Using a MFI-Type Zeolite Membrane
}

\author{
Bo Zhu ${ }^{1}$, Jun Hyun Kim ${ }^{2}$, Yong-Han Na ${ }^{2}$, Il-Shik Moon ${ }^{3}$, Greg Connor ${ }^{4}$, Shuichi Maeda ${ }^{4}$, \\ Gayle Morris ${ }^{5}$, Stephen Gray ${ }^{1}$ and Mikel Duke ${ }^{1, *}$
}

1 Institute for Sustainability and Innovation, College of Engineering and Science, Victoria University, Hoppers Lane, Werribee 3030, Australia; E-Mails: bo.zhu@vu.edu.au (B.Z.); stephen.gray@vu.edu.au (S.G.)

2 Chosun Refractory Co. Ltd., Taein Dong, Kwangyang-si, Jeonlanam-do 545-893, Korea;

E-Mails: jhkim82@chosunref.co.kr (J.H.K.); yongna@chosunref.co.kr (Y.-H.N.)

3 Department of Chemical Engineering, Sunchon National University, Maegok Dong, Suncheon 540-742, Korea; E-Mail: ismoon@sunchon.ac.kr

4 C.I. Ceramics (Aust.) Pty. Ltd., Rivulet Crescent, Albion Park Rail 2527, Australia; E-Mails: greg.connor@ciceramics.com.au (G.C.); shuichi.maeda@ciceramics.com.au (S.M.)

5 Research Services Office, Flinders University, Adelaide 5001, Australia;

E-Mail: gayle.morris@flinders.edu.au

* Author to whom correspondence should be addressed; E-Mail: mikel.duke@vu.edu.au; Tel.: +61-3-92917682; Fax: +61-3-92917696.

Received: 16 June 2013; in revised form: 8 July 2013 / Accepted: 9 July 2013 /

Published: 17 July 2013

\begin{abstract}
Zeolites are potentially a robust desalination alternative, as they are chemically stable and possess the essential properties needed to reject ions. Zeolite membranes could desalinate "challenging" waters, such as saline secondary effluent, without any substantial pre-treatment, due to the robust mechanical properties of ceramic membranes. A novel MFI-type zeolite membrane was developed on a tubular $\alpha-\mathrm{Al}_{2} \mathrm{O}_{3}$ substrate by a combined rubbing and secondary hydrothermal growth method. The prepared membrane was characterised by scanning electron microscopy (SEM), X-ray photoelectron spectroscopy (XPS) and single gas $\left(\mathrm{He}\right.$ or $\mathrm{N}_{2}$ ) permeation and underwent desalination tests with $\mathrm{NaCl}$ solutions under different pressures $(0.7 \mathrm{MPa}$ and $7 \mathrm{MPa})$. The results showed that higher pressure resulted in higher $\mathrm{Na}^{+}$rejection and permeate flux. The zeolite membrane achieved a good rejection of $\mathrm{Na}^{+}(\sim 82 \%)$ for a $\mathrm{NaCl}$ feed solution with a TDS (total dissolved solids) of $3000 \mathrm{mg} \cdot \mathrm{L}^{-1}$ at an applied pressure of $7 \mathrm{MPa}$ and $21^{\circ} \mathrm{C}$. To explore the
\end{abstract}


opportunity for high salinity and high temperature desalination, this membrane was also tested with high concentration $\mathrm{NaCl}$ solutions (up to TDS $90,000 \mathrm{mg} \cdot \mathrm{L}^{-1}$ ) and at $90{ }^{\circ} \mathrm{C}$. This is the first known work at such high salinities of $\mathrm{NaCl}$. It was found that increasing the salinity of the feed solution decreased both $\mathrm{Na}^{+}$rejection and flux. An increase in testing temperature resulted in an increase in permeate flux, but a decrease in ion rejection.

Keywords: desalination; MFI-type zeolite membrane; rubbing method; seeded secondary growth

\section{Introduction}

Membranes are now the state-of-the-art for water treatment, including most new desalination plants. However, the reverse osmosis (RO) membranes used for desalination are polymeric-based and have some common problems, such as biofouling, oxidation, metal oxide fouling, abrasion and clay and mineral scaling [1]. Polymeric RO membranes require strict pre-treatment, such as particle removal and removal of oxidants, such as chlorine. Despite the strict pre-treatment requirements, they eventually need to be replaced around every 5-7 years, due to damage caused either by foulants or the chemicals used for cleaning [2]. Therefore, research of alternative materials, such as inorganic membranes for desalination, is needed to address these material-based limitations.

Nanoporous inorganic membranes have been studied both theoretically and experimentally to reject ions by filtration, utilising single layers [3] and a novel bilayer concept [4,5]. There have been some studies to date applying different membrane materials, such as zeolites [3,6-11], and hybrid organically bridged silica [5] for separation of salt from aqueous solutions. Zeolite materials are highly configurable through their chemistry and offer unique frameworks for a wide variety of applications, including chemical sensing, water treatment and chemical reaction [3,6-14]. Zeolites are crystalline, hydrated aluminosilicates [15], naturally formed or synthesised, with open structures, which may incorporate a range of small inorganic and organic species. The frameworks of the zeolitic materials, which form the channels and cavities, are constructed from tetrahedral groups (e.g., $\mathrm{AlO}_{4}, \mathrm{SiO}_{4}, \mathrm{PO}_{4}$, $\mathrm{BeO}_{4}, \mathrm{GaO}_{4}, \mathrm{GeO}_{4}$ and $\mathrm{ZnO}_{4}$ ) linked to each other by sharing of oxygen atoms [16]. The most common zeolites are based on $\mathrm{AlO}_{4}$ and $\mathrm{SiO}_{4}$ tetrahedrals linked together to form a three-dimensional network having pores of comparable molecular dimensions to many chemical substances [16-18]. The remarkable porous crystalline aluminosilicate structure of zeolites has led to their wide application as molecular sieves for the separation of gases and liquids [19].

Ceramic membranes made from zeolites have been shown to be promising candidates for desalination of saline water, including seawater, as they possess the nanoporous structure required to reject ions [6,11]. Zeolite membranes offer a chemically robust desalination option to desalinate "challenging" waters or even reduce the cost of current desalination by reducing the pre-treatment, replacement and cleaning costs of current polymer membrane technology. Zeolite membranes may be used as an alternative to polymeric membranes for treatment of complex wastewater containing organic solvents and radioactive elements [6,10]. Since a molecular dynamic simulation study carried out by Lin and Murad [11] demonstrated that zeolite pore structure is ideally suited to reject ions, several research groups 
have explored the possibility of using MFI-type zeolite membranes for desalination [6-10]. The MFI-type zeolite has orthorhombic crystal symmetry with nearly cylindrical, 10-member ring channels [20]. The aperture size of the MFI-type zeolite is approximately $0.56 \mathrm{~nm}$ [8], which is smaller than the sizes of hydrated ions (e.g., $\mathrm{Na}^{+} 0.716 \mathrm{~nm}, \mathrm{Cl}^{-} 0.664 \mathrm{~nm}$ ), but larger than the kinetic diameter of water $(0.276 \mathrm{~nm})$ [21]. Performance testing of MFI type zeolite membranes working in reverse osmosis demonstrated that high rejections of even the smallest ions, including $\mathrm{Na}^{+}$, are achievable $[6,9]$. Recently, researchers have also attempted to treat oily water, produced water and radioactive solutions using zeolite membranes [22-25]. It was found that zeolitic membranes had great potential for separation of dissolved organics from aqueous solution and can also be used to treat low level radioactive wastes through the pervaporation process. However, little work has been carried out to explore the influence of high salinity and temperatures on the desalination performance of zeolite membranes.

In this study, we deposited MFI-type zeolite seeds on the outer surface of a tubular $\alpha-\mathrm{Al}_{2} \mathrm{O}_{3}$ support using the rubbing method [26,27] and then used secondary hydrothermal growth to prepare a MFI-type zeolite membrane. The prepared membrane was evaluated by gas permeation $\left(\mathrm{He}\right.$ and $\left.\mathrm{N}_{2}\right)$ and then underwent desalination performance testing with $\mathrm{NaCl}$ solutions under different conditions. The effects of $\mathrm{NaCl}$ feed concentration, applied pressure and temperature on membrane performance were investigated.

\section{Results and Discussion}

\subsection{Gas Permeation}

Gas permeation was used to evaluate the intactness of the zeolite membrane. The permeation of single gas $\left(\mathrm{He}\right.$ or $\left.\mathrm{N}_{2}\right)$ measured for the prepared zeolite membrane is shown in Table 1. The gas permeation results for the bare $\alpha-\mathrm{Al}_{2} \mathrm{O}_{3}$ support are also included in Table 1 for comparison. Since the membrane could adsorb water from air and water molecules can occupy the tight micropores of the zeolite structure and, thus, affect the gas permeability of the membrane, a gas permeation test was carried out on the zeolite membrane before and after drying at $100{ }^{\circ} \mathrm{C}$ in air to eliminate this effect. It can be seen from Table 1 that the permeance of $\mathrm{He}$ or $\mathrm{N}_{2}$ for the membrane measured was $\sim 30-40$-times smaller than that of the bare tube, indicating that a rate limiting zeolite layer was formed on the surface of the support. The $\mathrm{He} / \mathrm{N}_{2}$ permselectivities (determined by the ratio of single gas permeances) for the membrane were smaller than 2.6 (Knudsen $\mathrm{He} / \mathrm{N}_{2}$ permselectivity), suggesting that the membrane might have pores larger than those capable of Knudsen selectivity. However, there is no evidence to show that salt rejection correlates with $\mathrm{He} / \mathrm{N}_{2}$ permselectivity.

Table 1. Permeation of $\mathrm{He}$ and $\mathrm{N}_{2}$ for the bare $\alpha-\mathrm{Al}_{2} \mathrm{O}_{3}$ support and zeolite membrane before and after drying at $100{ }^{\circ} \mathrm{C}$ in air for $1 \mathrm{~h}$. For reference, the Knudsen permselectivity of $\mathrm{He}$ to $\mathrm{N}_{2}$ is 2.6 .

\begin{tabular}{cccc}
\hline Sample & $\begin{array}{c}\text { He permeation } \\
\left(\mathbf{m o l} \cdot \mathbf{m}^{-\mathbf{2}} \cdot \mathbf{s}^{-\mathbf{1}} \cdot \mathbf{P a}^{-\mathbf{1}}\right)\end{array}$ & $\begin{array}{c}\mathbf{N}_{\mathbf{2}} \text { permeation } \\
\left(\mathbf{m o l} \cdot \mathbf{m}^{-\mathbf{2}} \cdot \mathbf{s}^{-\mathbf{1}} \cdot \mathbf{P a}^{-\mathbf{1}}\right)\end{array}$ & $\mathbf{H e} / \mathbf{N}_{\mathbf{2}}$ permselectivity \\
\hline Bare tube-new & $39.1 \times 10^{-7}$ & $27.6 \times 10^{-7}$ & 1.4 \\
Bare tube-dry & $30.5 \times 10^{-7}$ & $24.6 \times 10^{-7}$ & 1.2 \\
Membrane-new & $1.3 \times 10^{-7}$ & $0.7 \times 10^{-7}$ & 1.8 \\
Membrane-dry & $1.3 \times 10^{-7}$ & $0.7 \times 10^{-7}$ & 1.8 \\
\hline
\end{tabular}




\subsection{Desalination Performance}

To explore the opportunity for high salinity and high temperature desalination, the performance of the prepared MFI-type zeolite membrane was evaluated by $\mathrm{NaCl}$ solutions with different concentrations (e.g., $\mathrm{NaCl}$ concentrations of 3000 to $90,000 \mathrm{mg} \cdot \mathrm{L}^{-1}$ ) under various operating conditions (e.g., pressure of $0.7 \mathrm{MPa}$ or $7 \mathrm{MPa}$ and temperature of $21{ }^{\circ} \mathrm{C}$ or $90{ }^{\circ} \mathrm{C}$ ). The high salt concentrations $\left(>35,000 \mathrm{mg} \cdot \mathrm{L}^{-1}\right)$ tested in the current work reflect the typical upper limit of commercial polymeric RO membranes used to desalinate seawater. However, polymer desalination membranes generally cannot be operated at $90{ }^{\circ} \mathrm{C}$, and the exploration in this work presents a novel opportunity for high temperature desalination. An application of high temperature desalination is in cases of naturally hot water (e.g., hot saline groundwater) and saline waters in industry that would normally be cooled to $<40{ }^{\circ} \mathrm{C}$ to allow treatment by polymer RO membrane. The osmotic pressures needed for desalination of the above $\mathrm{NaCl}$ solutions were estimated by Equation (1) [28] and are summarised in Table 2. The effective pressure for $\mathrm{NaCl}$ solutions with different concentrations can also be calculated according to Equation (2):

$$
\begin{gathered}
\pi=i M R T \\
p_{\text {effective }}=p_{\text {total }}-\left(\pi_{\text {seed }}-\pi_{\text {permeate }}\right)
\end{gathered}
$$

where $\pi$ is the osmotic pressure (atm), $i$ is the dimensionless Van 't Hoff factor, $M$ is the molarity of the salt in solution, $R$ is the ideal gas constant $\left(0.0821 \mathrm{~L} \cdot \mathrm{atm} \cdot \mathrm{K}^{-1} \cdot \mathrm{mol}^{-1}\right)$ and $T$ is temperature $(\mathrm{K})$. For simple binary electrolytes, like $\mathrm{NaCl}, i=1.8$ represented incomplete dissociation (ion pairing) [28]. $p_{\text {effective }}$ is the effective pressure $(\mathrm{MPa}), p_{\text {total }}$ is the applied gauge pressure (MPa) and $\pi_{\text {feed }}$ and $\pi_{\text {permeate }}$ are the osmotic pressures $(\mathrm{MPa})$ calculated from Equation (1) for the feed solution and permeate, respectively.

Table 2. Osmotic pressures determined by Equation (1) for the conditions used in this work.

\begin{tabular}{ccc}
\hline NaCl concentration $\left(\mathbf{m g} \cdot \mathbf{L}^{-\mathbf{1}}\right)$ & Temperature $\left({ }^{\circ} \mathbf{C}\right)$ & $\boldsymbol{\pi} \mathbf{( M P a})$ \\
\hline 3000 & 21 & 0.23 \\
3000 & 90 & 0.28 \\
35,000 & 21 & 2.6 \\
50,000 & 21 & 3.8 \\
70,000 & 21 & 5.3 \\
90,000 & 21 & 6.8 \\
\hline
\end{tabular}

The results for desalination of a $\mathrm{NaCl}$ solution with low salt concentration (TDS $3000 \mathrm{mg} \cdot \mathrm{L}^{-1}$ ) under different pressures and temperatures are shown in Figure 1. It can be seen that the prepared MFI-type zeolite membrane achieved a reasonable $\mathrm{Na}^{+}$rejection $(\sim 82 \%)$ with a flux of $\sim 7 \mathrm{~L} \cdot \mathrm{m}^{-2} \cdot \mathrm{h}^{-1}$ for a $3000 \mathrm{mg} \cdot \mathrm{L}^{-1} \mathrm{NaCl}$ feed solution at a high applied pressure of $7 \mathrm{MPa}$ and $21{ }^{\circ} \mathrm{C}$. Further testing with the same feed solution under a low applied pressure of $0.7 \mathrm{MPa}$ and at the same temperature $\left(21^{\circ} \mathrm{C}\right)$ showed a lower level of $\mathrm{Na}^{+}$rejection $(\sim 37 \%)$ and a significant decline in flux $\left(\sim 0.1 \mathrm{~L} \mathrm{~m}^{-2} \cdot \mathrm{h}^{-1}\right)$ when compared with the results obtained at $7 \mathrm{MPa}$. This result is supported by previous research [8] where rejection increased with pressure on zeolite membranes, because water is more strongly affected by total pressure. $\mathrm{Li}$ and co-workers [6] also reported a $\mathrm{Na}^{+}$rejection of $\sim 77 \%$ on an MFI-type zeolite membrane with a stabilised water flux of $0.112 \mathrm{~L} \cdot \mathrm{m}^{-2} \cdot \mathrm{h}^{-1}$ for a single $0.1 \mathrm{M} \mathrm{NaCl}\left(5850 \mathrm{mg} \cdot \mathrm{L}^{-1}\right)$ feed 
solution with a transmembrane pressure of $2.07 \mathrm{MPa}$. While the $\mathrm{Na}^{+}$rejection $(\sim 37 \%)$ achieved in this study for a single $\mathrm{NaCl}$ feed solution of $3000 \mathrm{mg} \cdot \mathrm{L}^{-1}$ under an applied pressure of $0.7 \mathrm{MPa}$ is practically too low, the current work aims to explore the effects of high salinity, pressure and temperature on membrane performance.

Figure 1. $\mathrm{Na}^{+}$rejection and flux on the zeolite membrane for the $\mathrm{NaCl}$ feed solution (total dissolved solids (TDS) of $3000 \mathrm{mg} \cdot \mathrm{L}^{-1}$ ) under different applied pressures and temperatures.

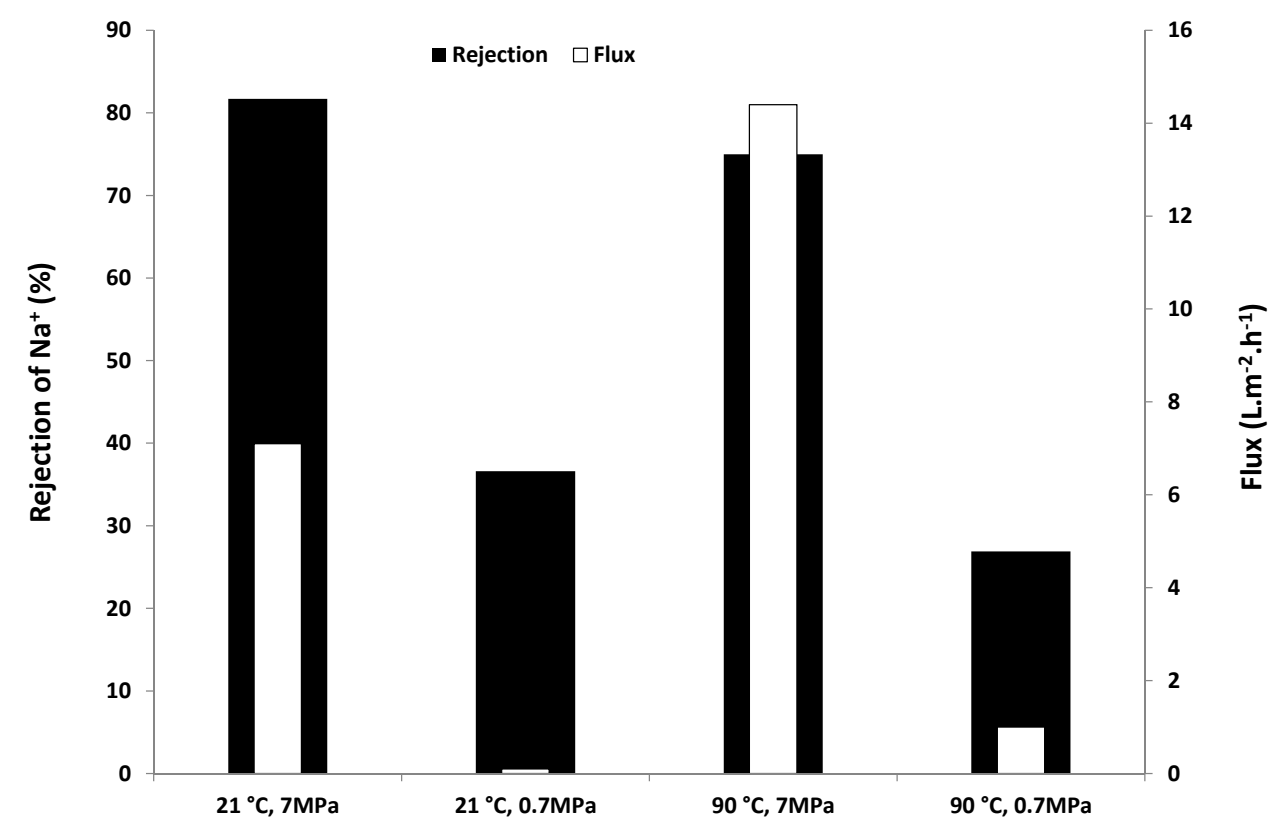

The results obtained from the tests at $90{ }^{\circ} \mathrm{C}$ at different pressures showed the same trend for $\mathrm{Na}^{+}$ rejection and flux as that of $21^{\circ} \mathrm{C}$. However, a further decrease in the rejection of $\mathrm{Na}^{+}$and a significant increase in the flux for both applied pressures $(0.7 \mathrm{MPa}$ and $7 \mathrm{MPa})$ were observed when increasing the testing temperature from $21^{\circ} \mathrm{C}$ to $90{ }^{\circ} \mathrm{C}$ (Figure 1).

These results appear to follow the effect related to change in effective pressure [Equation (2)]. The osmotic pressures of the solutions used in this work are shown in Table 2. Based on the finding that water is most sensitive to pressure, decreasing rejection is clear when pressure is reduced, as less effective pressure is available for RO. For example, the effective pressure [estimated from Equation (2)] decreased from 6.8 $\mathrm{MPa}$ to $0.6 \mathrm{MPa}$ when the applied gauge pressure was reduced from $7 \mathrm{MPa}$ to $0.7 \mathrm{MPa}$. Furthermore, there is a slight increase in osmotic pressure with increased temperature, which would also lead to a reduced rejection, especially at low applied pressures (e.g., $0.7 \mathrm{MPa}$ ). Normally, this would happen in tandem with reduced flux, but activated diffusion was accelerated beyond this effect. An increase in permeate flux with an increase in temperature was also observed by Li et al. [8]. They found in their study that increasing the feed temperature up to $50{ }^{\circ} \mathrm{C}$ significantly increased both water and ion fluxes. Possible changes in the pore characteristics of the membrane's MFI structure [29] and a decrease in the extent of hydration of ions [30] when increasing the temperature may also contribute to the increase in flux and decrease in ion rejection. A dedicated diffusion study is required to properly investigate the diffusion of water and ions coupled with the effects of osmotic pressure and temperature-driven diffusion of both ions and water molecules. 
In the current work, the effect of the solution salinity on membrane performance was also investigated. Figure 2 compares the results from further desalination tests on different concentrations of $\mathrm{NaCl}$ feed solutions $\left(35,000,50,000,70,000\right.$ and $\left.90,000 \mathrm{mg} \cdot \mathrm{L}^{-1}\right)$ at $7 \mathrm{MPa}$ and $21{ }^{\circ} \mathrm{C}$ with those obtained for $3000 \mathrm{mg} \cdot \mathrm{L}^{-1}$ at the same conditions. Figure 3 shows the effect of salinity on the effective pressure [estimated from Equation (2)] and specific flux, which was estimated according to the following equation:

$$
F_{s}=\frac{F}{p_{\text {effective }}}
$$

where $F_{s}\left(\mathrm{~L} \cdot \mathrm{m}^{-2} \cdot \mathrm{h}^{-1} \cdot \mathrm{MPa}^{-1}\right)$ is the specific flux and $F\left(\mathrm{~L} \cdot \mathrm{m}^{-2} \cdot \mathrm{h}^{-1}\right)$ is the flux obtained from Figure 2 for a certain tested $\mathrm{NaCl}$ concentration.

The results showed that both $\mathrm{Na}^{+}$rejection and flux decreased with increasing salinity (Figure 2). Rejection decreased from around $80 \%$ to $50 \%$ when the concentration of the feed $\mathrm{NaCl}$ solution was increased from 3000 to $90,000 \mathrm{mg} \cdot \mathrm{L}^{-1}$. Flux decreased from 7 to $3 \mathrm{~L} \cdot \mathrm{m}^{-2} \cdot \mathrm{h}^{-1}$ over the same concentration range tested. This is reasonable, as a higher salinity solution needs higher osmotic pressure (Table 2), thus resulting in less effective pressure available for RO compared to that of a lower salinity solution under the same applied pressure (Figure 3). However, regardless of the higher concentration tested in this study, rejection decreased, such that the osmotic pressure difference remained below the applied pressure $(7 \mathrm{MPa})$. For example, at $90,000 \mathrm{mg} \cdot \mathrm{L}^{-1}$, rejection decreased to $50 \%$, so this salinity difference was $45,000 \mathrm{mg} \cdot \mathrm{L}^{-1}$, corresponding to an osmotic pressure of about 3.4 MPa [based on Equation (1)], which is around half of the applied pressure (Figure 3). It can also be seen from Figure 3 that the specific flux remained almost unchanged when the concentration of the feed $\mathrm{NaCl}$ solution was increased from 3000 to $90,000 \mathrm{mg} \cdot \mathrm{L}^{-1}$. This confirmed that the decrease in flux with the increased salinity of feed $\mathrm{NaCl}$ solutions was caused by changes in the effective driving pressure.

Figure 2. $\mathrm{Na}^{+}$rejection and flux on the zeolite membrane for the feed solutions with different $\mathrm{NaCl}$ concentrations (TDS 3000 to $90,000 \mathrm{mg} \cdot \mathrm{L}^{-1}$ ) at an applied gauge pressure of $7 \mathrm{MPa}$ and $21^{\circ} \mathrm{C}$.

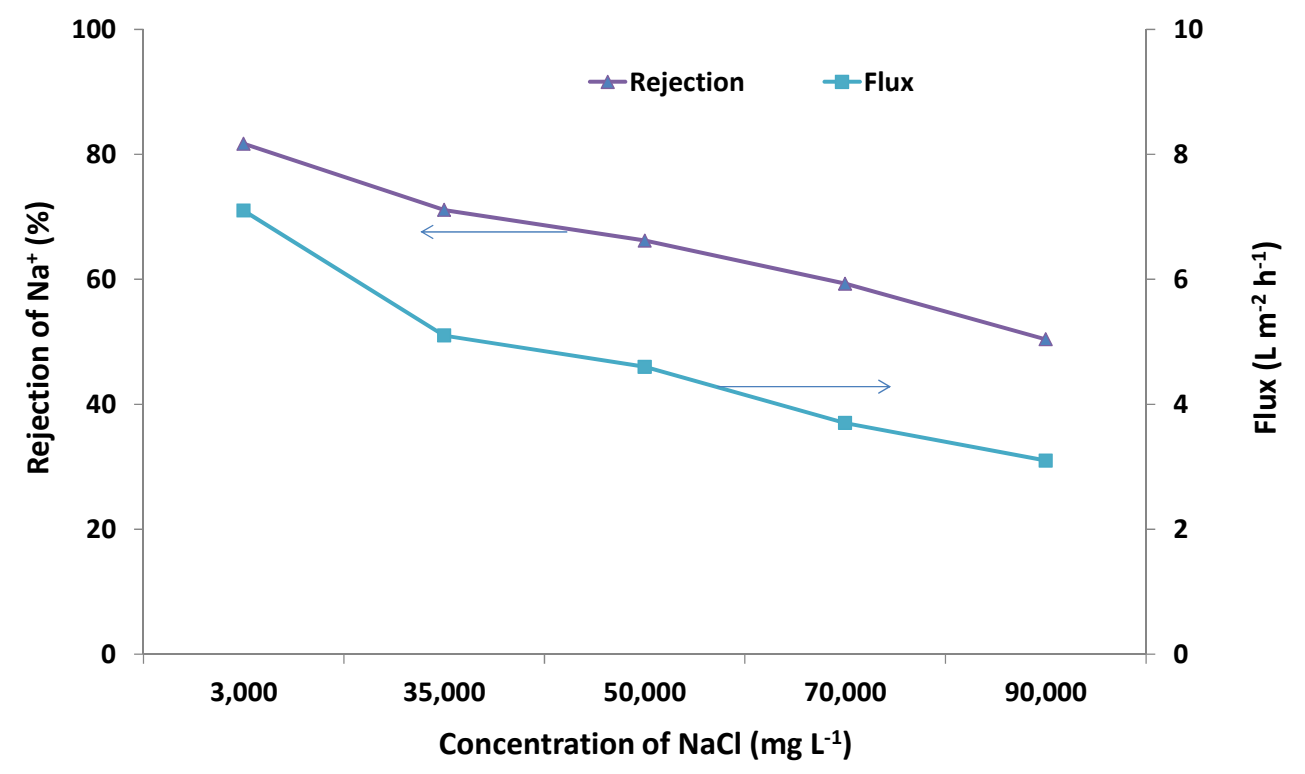


Figure 3. Effective pressure and specific flux on the zeolite membrane for the feed solutions with different $\mathrm{NaCl}$ concentrations (TDS 3000 to $90,000 \mathrm{mg} \cdot \mathrm{L}^{-1}$ ) at an applied pressure of $7 \mathrm{MPa}$ (gauge) and $21^{\circ} \mathrm{C}$.

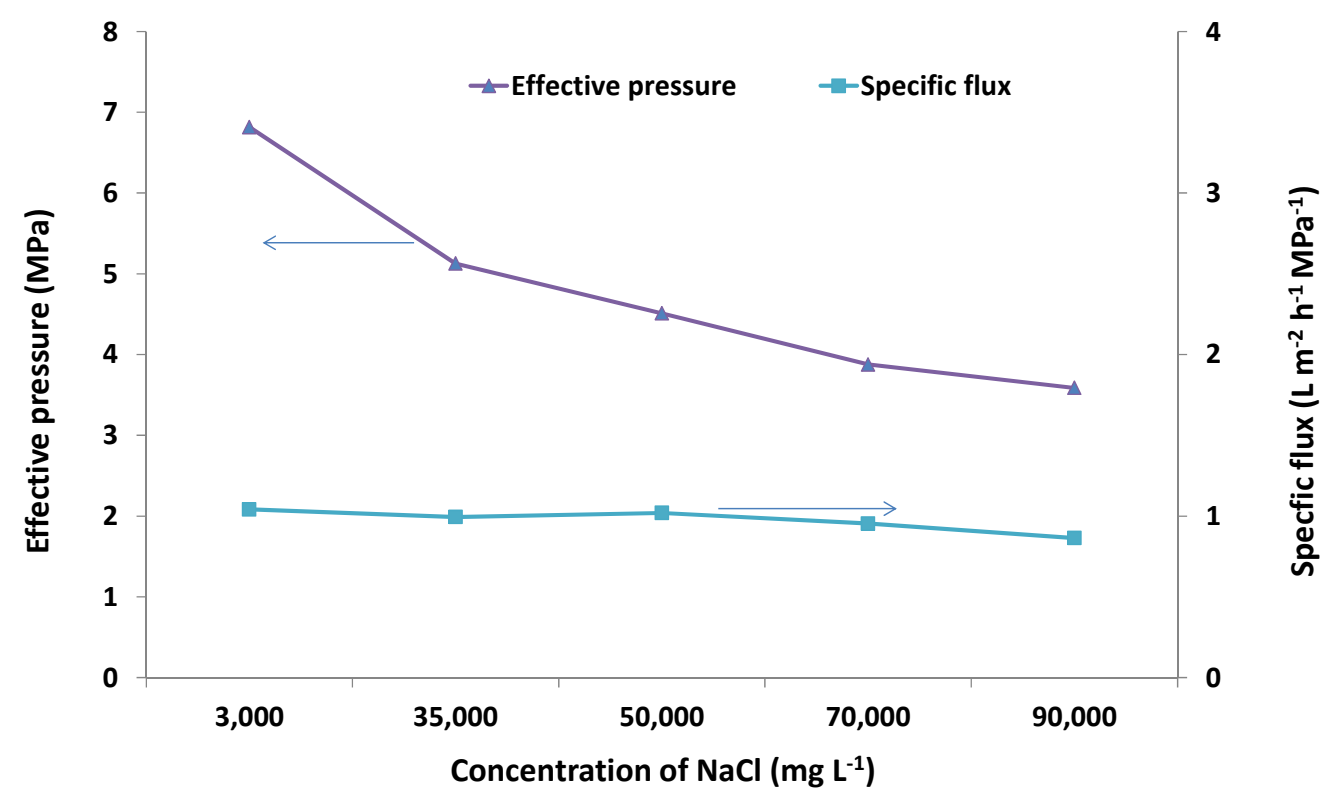

\subsection{SEM}

SEM was employed to investigate the morphology of the zeolite membrane before and after $\sim 90 \mathrm{~h}$ desalination testing with $\mathrm{NaCl}$ solutions. Figure 4 shows the SEM images of the surface of the bare $\alpha-\mathrm{Al}_{2} \mathrm{O}_{3}$ support and the top layer of the MFI-type zeolite membrane. The uncoated support presented plate-like particles with high porosity (Figure 4a). The image (Figure 4b) of the as-synthesised zeolite membrane surface showed typical randomly orientated MFI-type zeolite crystals, confirming the formation of a zeolite layer on the $\alpha-\mathrm{Al}_{2} \mathrm{O}_{3}$ support, as determined by gas permeation (Section 2.1). Most of the zeolite crystals laid randomly on the surface of the $\alpha-\mathrm{Al}_{2} \mathrm{O}_{3}$ support. Although SEM was not carried out on the cross-section of the membrane in this study, we expect the membrane thickness to be $\sim 3 \mu \mathrm{m}$, as measured for the other membranes prepared in our laboratory by the same procedures as used for the current work. The top view (Figure 4c) of the surface of the tested membrane showed no significant change to the membrane structure after $\sim 90 \mathrm{~h}$ desalination testing under different conditions (e.g., pressures, temperatures). The membrane retained only some "loose" deposition of salts on the surface after $\sim 90 \mathrm{~h}$ desalination testing with $\mathrm{NaCl}$ solutions. The recent stability study carried out by Drobek, et al. [31] on zeolite membranes showed some permanent decay after up to $560 \mathrm{~h}$ desalination testing in pervaporation mode. This was due to the combined effects of ion exchange and water dissolution mechanisms. Despite this finding, we did not see a membrane performance loss in our study during a relatively shorter term $(\sim 90 \mathrm{~h})$ of desalination testing with $\mathrm{NaCl}$ solutions in filtration mode. 
Figure 4. SEM images on the surface of (a) $\alpha-\mathrm{Al}_{2} \mathrm{O}_{3}$ substrate; (b) original zeolite membrane; (c) desalination tested $(\sim 90 \mathrm{~h})$ zeolite membrane.

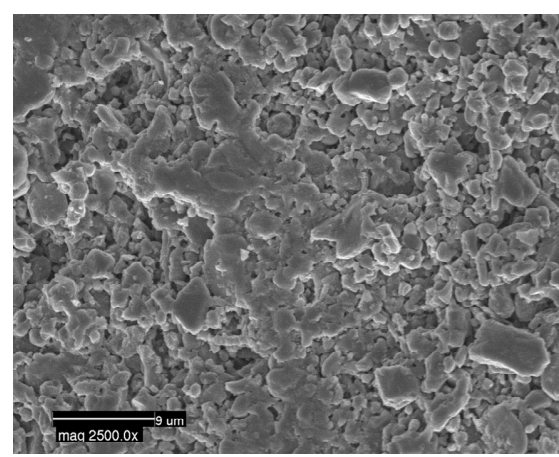

(a)

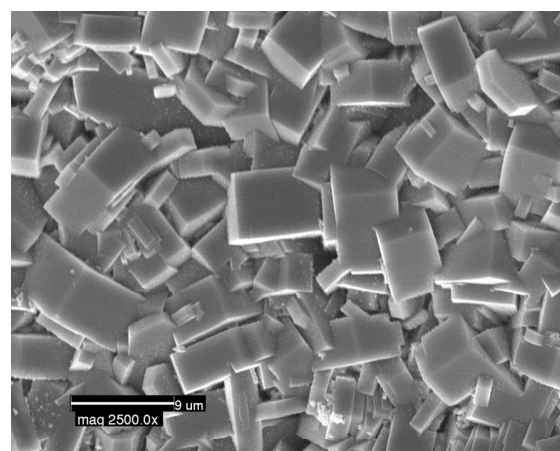

(b)

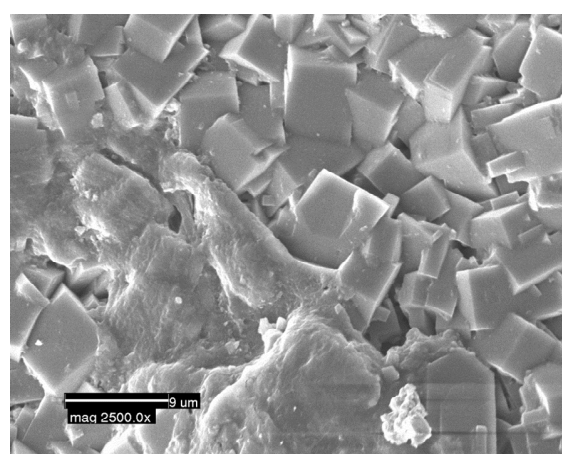

(c)

\subsection{XPS}

Elemental analysis was also conducted by XPS on the surface of the original and desalination tested MFI-type zeolite membrane to determine elemental changes after salt exposure. Prior to XPS measurements, the desalination tested membrane was permeated with deionised water and rinsed to remove loosely bound material (including ions). As shown in Table 3, $\mathrm{Na}$ and $\mathrm{Cl}$ signals were detected on the surface of the desalination tested membrane by XPS elemental analysis. This suggests that zeolites interacted with ions present in $\mathrm{NaCl}$ feed solution during desalination. The interactions between the MFI-type zeolites and ions when exposed to seawater or a single solution ( $\mathrm{NaCl}$ or $\mathrm{KCl})$ were also observed in our previous material adsorption studies [32,33]. $\mathrm{Cl}$ was also detected in the material, which has not been analysed in our previous studies [32,33]. Cl surface concentration was less than the Na surface concentration after desalination testing, potentially indicating a preference for $\mathrm{Na}$ in the negatively charged material [9]. It is clear from this result that XPS observes the presence of $\mathrm{Na}$ more strongly than $\mathrm{Cl}$. The X-rays will penetrate quite significantly into the sample, several microns at least, but excited electrons leave with very low energy and, thus, can only escape from the top 1-10 $\mathrm{nm}$ of the surface (the typically analysis is at a depth of $5 \mathrm{~nm}$ ) [34-36]. Therefore, $\mathrm{Cl}$ must be residing in locations shielded from the XPS analysis, potentially deeper within the grain boundaries, as opposed to the MFI zeolite surface and intrinsic pores.

Table 3. XPS analysis of elements on the bare $\alpha-\mathrm{Al}_{2} \mathrm{O}_{3}$ substrate, the original and the desalination tested zeolite membrane.

\begin{tabular}{cccc}
\hline Element & Bare tube (at \%) & Original membrane (at \%) & NaCl tested membrane (at \%) \\
\hline $\mathrm{O} 1 \mathrm{~s}$ & 18.3 & 31.2 & 35.4 \\
$\mathrm{C} 1 \mathrm{~s}$ & 54.8 & 40.8 & 33.2 \\
$\mathrm{Al} 2 \mathrm{p}$ & 15.9 & 2.0 & - \\
$\mathrm{Si} 2 \mathrm{p}$ & 3.0 & 22.7 & 24.7 \\
$\mathrm{Ca} 2 \mathrm{p}$ & 1.6 & 1.3 & 0.9 \\
$\mathrm{~N} 1 \mathrm{~s}$ & 2.4 & 2.0 & 2.7 \\
$\mathrm{Cl} 2 \mathrm{p}$ & 0.8 & - & 0.9 \\
$\mathrm{Na} 2 \mathrm{~s}$ & 3.2 & - & 2.2 \\
\hline
\end{tabular}




\section{Experimental Section}

\subsection{Preparation of MFI-Type Zeolite Membrane}

The MFI-type zeolite membrane was coated on a porous $\alpha-\mathrm{Al}_{2} \mathrm{O}_{3}$ tubular support (external diameter $15 \mathrm{~mm}$, internal diameter $10 \mathrm{~mm}$, length $25 \mathrm{~mm}, \sim 0.58 \mu \mathrm{m}$ nominal pore size, Chosun Refractory Co. Ltd., Korea) by a secondary growth technique, which involved depositing zeolite seeds on the support using a rubbing method [26,27] followed by growth of the membrane under hydrothermal conditions [9]. Prior to membrane preparation, the bare $\alpha-\mathrm{Al}_{2} \mathrm{O}_{3}$ tube was tested under high pressure up to $10 \mathrm{MPa}$, confirming that the ceramic tube used in this study for membrane preparation can withstand the desalination test system desired pressure (e.g., $7 \mathrm{MPa}$ ). The zeolite seed powders (ZSM-5, $\mathrm{SiO}_{2} / \mathrm{Al}_{2} \mathrm{O}_{3}=360$ ) used for seed-deposition were supplied by ACS Material, USA. The particle size distribution of the zeolite seeds used in this study was determined by a Zetasizer (Malvern Instruments-nano-series) to be between $1000 \mathrm{~nm}$ and $3000 \mathrm{~nm}$ (peaking at $\sim 1800 \mathrm{~nm}$ ) in our laboratory (Figure 5). The hydrothermal secondary growth was carried out in a growth solution of $2 \mathrm{~mL}$ of $1 \mathrm{M}$ tetra-propyl ammonium hydroxide (TPAOH) (Aldrich), $2 \mathrm{~mL}$ of tetraethyl orthosilicate (TEOS) (98\%, Aldrich) and $36 \mathrm{~mL}$ DI water at $180{ }^{\circ} \mathrm{C}$ for $16 \mathrm{~h}$. After growth, the membrane was washed in deionised water to remove loose precipitate and was then calcined at $500{ }^{\circ} \mathrm{C}$ for $4 \mathrm{~h}$.

Figure 5. Zetasizer measured particle size distribution of the zeolite seeds.

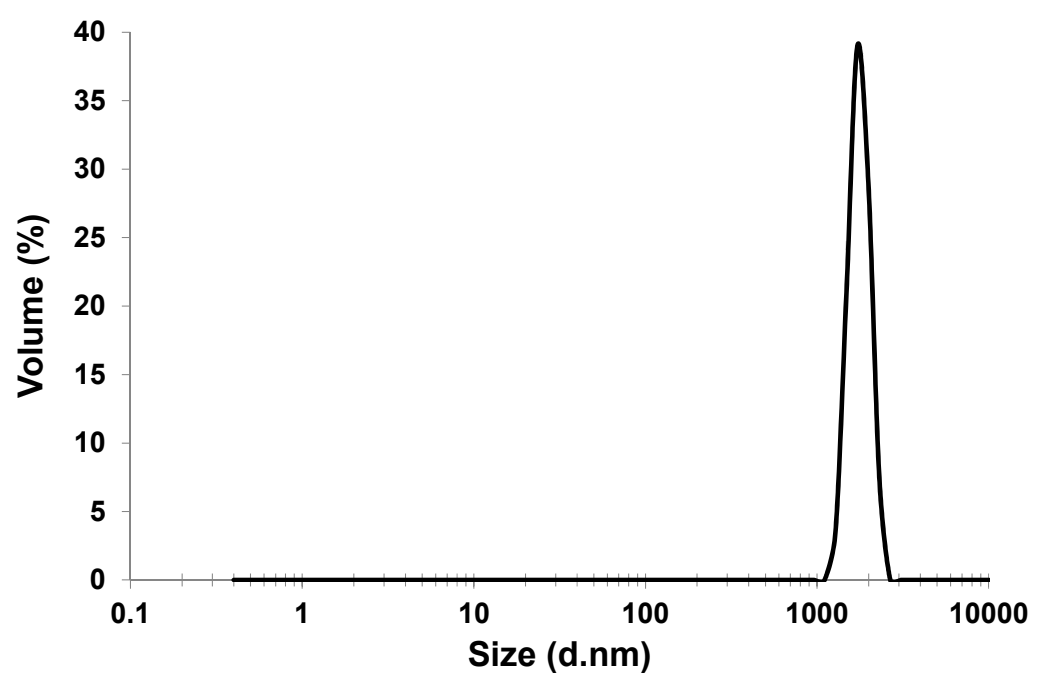

\subsection{Characterisation}

The original and desalination tested MFI-type zeolite membrane was characterised by SEM and XPS to determine any changes in membrane structure, morphology and surface elements after long-term desalination testing under different conditions. Prior to SEM and XPS measurements, the desalination tested membrane underwent deionised water permeation to remove adsorbed material (including ions).

SEM images were obtained from the secondary electron detector of a CamScan MX2500 microscope (CamScan Optics, Cambridge, UK) using a $10 \mathrm{kV}$ electron beam with a working distance of $2.2 \mathrm{~mm}$. 
XPS spectra were recorded using a Leybold-Heraeus "LHS-10" XPS instrument, with EA-10/100 concentric hemispherical analyser, operating in constant retarding ratio mode for survey scans and constant analysis energy mode for high resolution scans. The base pressure was $\sim 1 \times 10^{-9}$ Torr and the operating pressure $\sim 1 \times 10^{-8}$ Torr during analysis. Photoelectrons were produced by a SPECS "XR-50" $\mathrm{X}$-ray source, utilising the $\mathrm{Mg}$-k $\alpha \mathrm{X}$-ray anode operating at an energy of $1253.6 \mathrm{eV}$. Atomic concentrations for each element were determined from their XPS peak areas and their respective sensitivity factors.

Gas permeation (Figure 6) was used to evaluate the intactness of the synthesised zeolite membrane. The membrane was first installed into the stainless steel membrane housing and placed into the unit with temperature control. Permeation of either $\mathrm{He}$ or $\mathrm{N}_{2}$ was carried out by feeding the gas at $100 \mathrm{kPa}$ to the film-side of the membrane. Pressure decay occurred during the permeation test and was monitored by a TPI 665 digital manometer (Test Products International, Inc. USA). The pressure was recorded by a computer with TPI 665 Data Logger software. Permeation was calculated by normalising the data to the membrane area and the pressure drop measured by the manometer.

Figure 6. Schematic diagram of the gas permeation system.

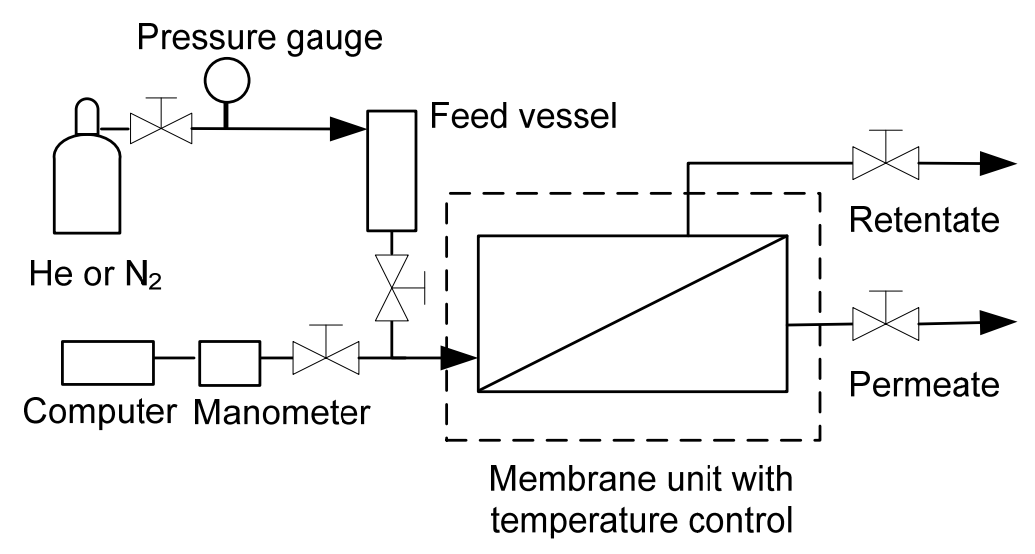

\subsection{Desalination Test}

The desalination performance of the zeolite membrane for $\mathrm{NaCl}$ solutions at different applied pressures and temperatures was evaluated in a desalination test system, as shown in Figure 7. The membrane was installed into the same membrane housing as used for gas permeation, and the feed solution (DI water or $\mathrm{NaCl}$ solution) was fed at a flow rate of $5 \mathrm{~mL} \cdot \mathrm{min}^{-1}$ by a high pressure piston pump (Series 1, LabAlliance, USA) with an applied gauge pressure of up to $7 \mathrm{MPa}$. The $\mathrm{NaCl}$ solutions (TDS 3000, 35,000, 50,000, 70,000 and 90,000 $\mathrm{mg} \cdot \mathrm{L}^{-1}$ ) were prepared from sodium chloride ACS reagent ( $\geq 99.0 \%$, Aldrich). Total dissolved solids (TDS) of the $\mathrm{NaCl}$ feed solutions and collected permeate samples were determined with a portable conductivity meter (Sension 156, HACH) and by converting the electrical conductivity measurements to TDS values via a pre-determined relationship. The rejection of $\mathrm{Na}^{+}$was estimated from the TDS values to determine the desalination performance of the membrane. 
Figure 7. Schematic diagram of the experimental system for membrane desalination.

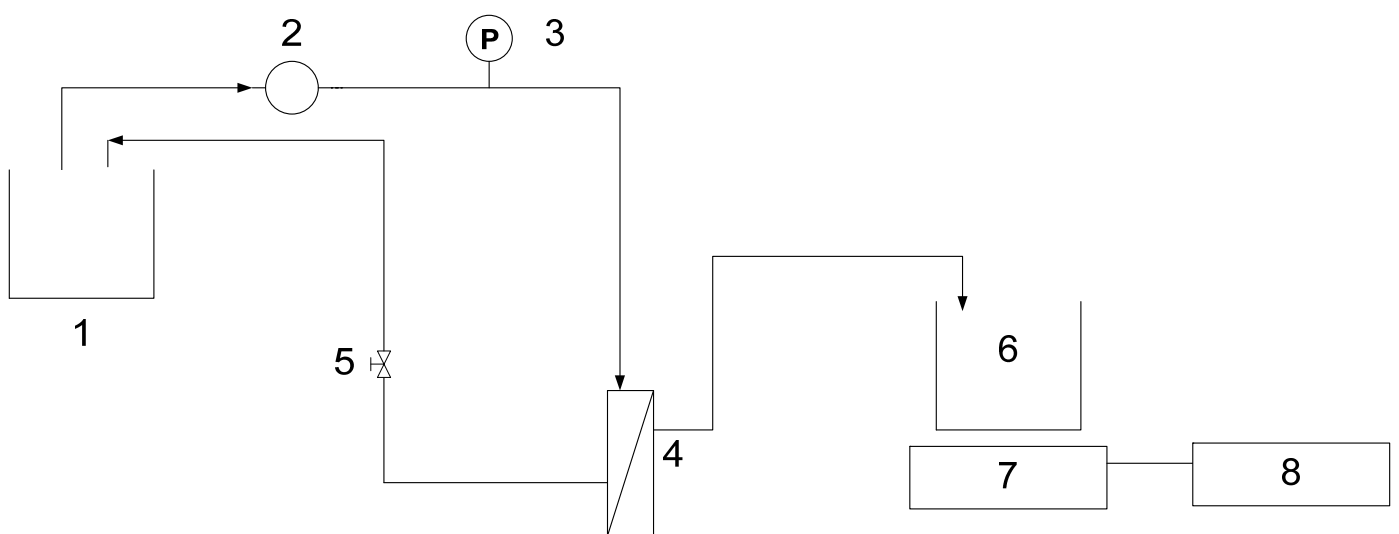

1. Feed vessel; 2. High pressure pump; 3. Pressure gauge; 4. Ceramic membrane; 5. Pressure control/isolation valve; 6. Permeate collection; 7. Balance; 8. Computer

\section{Conclusions}

A novel MFI-type zeolite membrane was developed by deposition of commercially available zeolite seeds on $\alpha-\mathrm{Al}_{2} \mathrm{O}_{3}$ substrate followed by secondary hydrothermal growth. Desalination through the prepared MFI-type zeolite membrane was investigated for $\mathrm{NaCl}$ solutions with different TDS (3000, $35,000,50,000,70,000$ and $\left.90,000 \mathrm{mg} \cdot \mathrm{L}^{-1}\right)$. Good rejection of $\mathrm{Na}^{+}(\sim 82 \%)$ was achieved for an $\mathrm{NaCl}$ feed solution (TDS $3000 \mathrm{mg} \cdot \mathrm{L}^{-1}$ ) at an operating pressure of $7 \mathrm{MPa}$ and room temperature by the zeolite membrane. Increasing operating temperature increased the permeation flux of the zeolite membrane, but decreased ion rejection. When increasing the salinity of the feed solution, both $\mathrm{Na}^{+}$ rejection and flux were decreased. The flux variations at different salt concentrations can be explained by changes in the effective driving pressure, as the specific flux was constant. SEM measurements confirmed the formation of randomly orientated MFI-type zeolite membrane film on the surface of an $\alpha-\mathrm{Al}_{2} \mathrm{O}_{3}$ support, but showed no changes in structure after desalination testing with $\mathrm{NaCl}$ feed solutions. However, XPS elemental analysis detected $\mathrm{Na}$ and $\mathrm{Cl}$ signals on the surface of the desalination tested membrane, suggesting that interaction between zeolites and ions present in $\mathrm{NaCl}$ feed solution might have occurred during desalination. The results obtained in this study showed that MFI-type zeolite membranes have some potential applications, where high rejections $(>99.5 \%)$, like polymers, are not needed (e.g., brackish water treatment, industrial waste treatment or seawater pre-treatment) and for high temperature desalination.

\section{Acknowledgments}

This research was funded by the Australian Research Council through a Linkage Project (LP100200242), Chosun Refractory Co. Ltd. and C. I. Ceramics (Aust.) Pty. Ltd. The authors wish to thank Daniel Tune for performing the SEM analysis and Alex Sibley for performing the XPS analysis. 


\section{References}

1. Chesters, S.P.; Pena, N.; Gallego, S.; Fazel, M.; Armstrong, M.W.; del Vigo, F. Results from 99 Sea Water Reverse Osmosis (SWRO) Membrane Autopsies. In Proceedings of the IDA World Congress, Perth, Western Australia, Australia, 4-9 September 2011.

2. NRC (National Research Council). Review of the Desalination and Water Purification Technology Roadmap; The National Academic Press: Washington, DC, USA, 2004.

3. Cho, C.H.; Oh, K.Y.; Kim, S.K.; Yeo, J.G.; Sharma, P. Pervaporative seawater desalination using naa zeolite membrane: Mechanisms of high water flux and high salt rejection. J. Membr. Sci. 2011, 371, 226-238.

4. Samuel de Lint, W.B.; Zivkovic, T.; Benes, N.E.; Bouwmeester, H.J.M.; Blank, D.H.A. Electrolyte retention of supported Bi-layered nanofiltration membranes. J. Membr. Sci. 2006, 277, $18-27$.

5. Xu, R.; Wang, J.; Kanezashi, M.; Yoshioka, T.; Tsuru, T. Development of robust organosilica membranes for reverse osmosis. Langmuir 2011, 27, 13996-13999.

6. Li, L.X.; Dong, J.H.; Nenoff, T.M.; Lee, R. Desalination by reverse osmosis using mfi zeolite membranes. J. Membr. Sci. 2004, 243, 401-404.

7. Li, L.X.; Dong, J.H.; Nenoff, T.M.; Lee, R. Reverse osmosis of ionic aqueous solutions on a mfi zeolite membrane. Desalination 2004, 170, 309-316.

8. Li, L.X.; Dong, J.H.; Nenoff, T.M. Transport of water and alkali metal ions through mfi zeolite membranes during reverse osmosis. Sep. Purif. Technol. 2007, 53, 42-48.

9. Duke, M.; O’Brien-Abraham, J.; Milne, N.; Zhu, B.; Lin, Y.S.; Diniz da Costa, J.C. Seawater desalination performance of mfi type membranes made by secondary growth. Sep. Purif. Technol. 2009, 68, 343-350.

10. Kazemimoghadam, M.; Mohammadi, T. Synthesis of MFI zeolite membranes for water desalination. Desalination 2007, 206, 547-553.

11. Lin, J.; Murad, S. A computer simulation study of the separation of aqueous solutions using thin zeolite membranes. Mol. Phys. 2001, 99, 1175-1181.

12. Deng, Y.; Deng, C.; Qi, D.; Liu, C.; Liu, J.; Zhang, X.; Zhao, D. Synthesis of core/shell colloidal magnetic zeolite microspheres for the immobilization of trypsin. Adv. Mater. 2009, 21, $1377-1382$.

13. Doocey, D.J.; Sharratt, P.N.; Cundy, C.S.; Plaisted, R.J. Zeolite-mediated advanced oxidation of model chlorinated phenolic aqueous waste: Part 2: Solid phase catalysis. Process. Saf. Environ. Prot. 2004, 82, 359-364.

14. Wang, W.; Zhou, M.; Mao, Q.; Yue, J.; Wang, X. Novel nay zeolite-supported nanoscale zero-valent iron as an efficient heterogeneous fenton catalyst. Catal. Commun. 2010, 11, 937-941.

15. Coronas, J. Present and future synthesis challenges for zeolites. Chem. Eng. J. 2010, 156, 236-242.

16. Weller, M.T. Inorganic Materials; Oxford University Press Inc.: New York, NY, USA, 1994; pp. $71-81$. 
17. Breck, D.W. Zeolite Molecular Sieves-Structure, Chemistry, and Use; Wiley: New York, NY, USA, 1974.

18. Kaduk, J.A.; Faber, J. Crystal structure of zeolite Y as a function of ion exchange. Rigaku J. 1995, $12,14-34$.

19. Lin, Y.S.; Duke, M.C. Recent progress in polycrystalline zeolite membrane research. Curr. Opin. Chem. Eng. 2013, 2, 209-216.

20. Baerlocher, C.; McCusker, L.B. Database of zeolite structures. Available online: http://www.Izastructure.org/databases/ (accessed on 11 July 2013).

21. Nightingale, E.R., Jr. Phenomenological theory of ion solvation. Effective radii of hydrated ions. J. Phys. Chem. 1959, 63, 1381-1387.

22. Cui, J.; Zhang, X.; Liu, H.; Liu, S.; Yeung, K.L. Preparation and application of zeolite/ceramic microfiltration membranes for treatment of oil contaminated water. J. Membr. Sci. 2008, 325, $420-426$.

23. Malekpour, A.; Millani, M.R.; Kheirkhah, M. Synthesis and characterization of a NAA zeolite membrane and its applications for desalination of radioactive solutions. Desalination 2008, 225, 199-208.

24. Li, L.; Liu, N.; McPherson, B.; Lee, R. Influence of counter ions on the reverse osmosis through MFI zeolite membranes: Implications for produced water desalination. Desalination 2008, 228, $217-225$.

25. Liu, N.; Li, L.; McPherson, B.; Lee, R. Removal of organics from produced water by reverse osmosis using MFI-type zeolite membranes. J. Membr. Sci. 2008, 325, 357-361.

26. Lee, J.S.; Kim, J.H.; Lee, Y.J.; Jeong, N.C.; Yoon, K.B. Manual assembly of microcrystal monolayers on substrates. Angew. Chem. Int. Ed. Engl. 2007, 46, 3087-3090.

27. Yoo, W.C.; Stoeger, J.A.; Lee, P.-S.; Tsapatsis, M.; Stein, A. High-performance randomly oriented zeolite membranes using brittle seeds and rapid thermal processing. Angew. Chem. Int. Ed. Engl. 2010, 49, 8699-8703.

28. Osmosis equation. Available online: http://www.chemteam.info/solutions/osmosis-equation.html (accessed on 30 May 2013).

29. Fyfe, C.A.; Strobl, H.; Kokotailo, G.T.; Kennedy, G.J.; Barlow, G.E. Ultra-high-resolution/sup 29/Si solid-state mas nmr investigation of sorbate and temperature-induced changes in the lattice structure of zeolite ZSM-5. J. Am. Chem. Soc. 1988, 110, 3373-3380.

30. Chaplin, M. Water structure and science: Ion hydration and aqueous solutions of salts. Available online: http://www.lsbu.ac.uk/water/ions.html (accessed on 21 February 2013).

31. Drobek, M.; Yacou, C.; Motuzas, J.; Julbe, A.; Ding, L.; Diniz da Costa, J.C. Long term pervaporation desalination of tubular mfi zeolite membranes. J. Membr. Sci. 2012, 415-416, 816-823.

32. Zhu, B.; Zou, L.; Doherty, C.M.; Hill, A.J.; Lin, Y.S.; Hu, X.R.; Wang, H.T.; Duke, M. Investigation of the effects of ion and water interaction on structure and chemistry of silicalite MFI type zeolite for its potential use as a seawater desalination membrane. J. Mater. Chem. 2010, $20,4675-4683$. 
33. Zhu, B.; Doherty, C.M.; Hu, X.; Hill, A.J.; Zou, L.; Lin, Y.S.; Duke, M. Designing hierarchical porous features of ZSM-5 zeolites via $\mathrm{Si} / \mathrm{Al}$ ratio and their dynamic behavior in seawater ion complexes. Microporous Mesoporous Mater. 2013, 173, 78-85.

34. Kerber, S.J.; Barr, T.L.; Mann, G.P.; Brantley, W.A.; Papazoglou, E.; Mitchell, J.C. The complementary nature of X-ray photoelectron spectroscopy and angle-resolved X-ray diffraction. Part I: Background and theory. J. Mater. Eng. Perform. 1998, 7, 329-333.

35. X-ray photoelectron spectroscopy. Available online: http://en.wikipedia.org/wiki/X-ray_ photoelectron_spectroscopy (accessed on 11 June 2013).

36. Electron spectroscopy for chemical analysis (ESCA) aka X-ray photoelectron spectroscopy (XPS). Available online: http://www.foothills-analytical.com/ESCA.html (accessed on 11 June 2013).

(C) 2013 by the authors; licensee MDPI, Basel, Switzerland. This article is an open access article distributed under the terms and conditions of the Creative Commons Attribution license (http://creativecommons.org/licenses/by/3.0/). 